\title{
Elastic stiffness estimation of aggregate-ITZ system of concrete through matrix porosity and volumetric considerations: explanation and exemplification
}

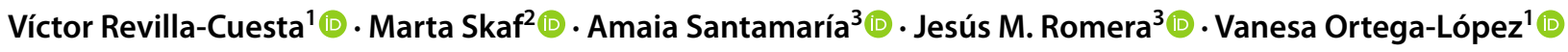

Received: 2 November 2021 / Revised: 20 December 2021 / Accepted: 12 January 2022 / Published online: 31 January 2022

(c) The Author(s) 2022

\begin{abstract}
The modulus of elasticity of a concrete depends on the elastic stiffness of both the cementitious matrix and the aggregate-ITZ system, which includes any slippage mechanisms under loading between the aggregate and the cementitious matrix within the interfacial transition zone (ITZ). A procedure is presented in this paper to estimate the elastic stiffness of an aggregate-ITZ system within a cementitious matrix, by considering the relative volumes and the porosities of the concrete components. The method was validated by determining the elastic stiffness of both the limestone-ITZ and the electric arc furnace slag (EAFS)-ITZ systems when embedded in a slag-based cementitious matrix. The greater stiffness of the EAFS-ITZ system in comparison with the natural aggregate system explained the higher strength and modulus of elasticity of the concrete following additions of EAFS. Moreover, having determined those parameters, the elastic moduli of concretes with a similar cementitious matrix could then be accurately estimated.
\end{abstract}

Keywords Elastic stiffness · Aggregate-ITZ system · Concrete's modulus of elasticity $\cdot$ Limestone aggregate $\cdot$ Electric arc furnace slag $\cdot$ Slag-based cementitious matrix

Marta Skaf

mskaf@ubu.es

Víctor Revilla-Cuesta

vrevilla@ubu.es

Amaia Santamaría

amaia.santamaria@ehu.es

Jesús M. Romera

jesusmaria.romera@ehu.es

Vanesa Ortega-López

vortega@ubu.es

1 Department of Civil Engineering, Escuela Politécnica Superior, University of Burgos, c/Villadiego s/n, 09001 Burgos, Spain

2 Department of Construction, Escuela Politécnica Superior, University of Burgos, c/Villadiego s/n, 09001 Burgos, Spain

3 Department of Mechanical Engineering, Escuela de Ingeniería de Bilbao I, University of the Basque Country, Pl. Ingeniero Torres Quevedo 1, 48013 Bilbao, Spain

\section{Introduction}

When incremental compressive loading is applied to a concrete element, concrete exhibits an elastoplastic behavior around the downward axis of the load. Initially, a linear elastic stress-strain behavior of the concrete is observed where the strain within the concrete is directly proportional to the stress that is applied to it. The proportionality constant is known as the modulus of elasticity [1]. When $55-60 \%$ of the compressive strength upon concrete failure is exceeded, the proportionality between the stress and the strain is progressively lost, and the material begins to exhibit a plastic behavior, characterized by the appearance of irreversible deformations in the stress-strain curve [2]. Unlike other materials, concrete presents no clear frontier between these two behavior zones [3].

A reasonable in-service safety margin for the structural design of a given concrete structure requires that its concrete components remain within the elastic zone [4]. Thus, the modulus of elasticity is a fundamental parameter for the structural design of concrete components, the accurate estimation of which is highly relevant in this process [5]. 
The modulus of elasticity of concrete is a complex property, which depends on numerous factors. On the one hand, it depends on the curing conditions, since moist curing causes concrete to develop greater strength and elastic stiffness than when dry curing is conducted [6]. Therefore, the environmental conditions during its placement in a real structure significantly affect its elastic stiffness [7]. Furthermore, the compaction process has to guarantee adequate homogeneity in the concrete mix when it is poured to obtain the desired elastic-stiffness level [8]. On the other hand, its composition also plays a fundamental role, since, rather than homogeneous, the composition of a concrete composite, in the hardened state, basically consists of a cementitious matrix and various sorts of aggregate. Three key aspects related to its variable composition condition its elastic stiffness, which as a consequence yield a wide range of values for the modulus of elasticity:

- Composition (quality) of the cementitious matrix. The use of different types of binders or ultrafine aggregates will alter the modulus of elasticity [9]. The cementitious matrix is also defined by porosity, such that the greater its porosity, the more deformable the concrete [10].

- Type of aggregate. The testing of different rock specimens has shown that each type of rock has a different modulus of elasticity $[11,12]$. Clearly, therefore, the elastic deformability of each type of aggregate will also differ [13].

- Finally, the interfacial transition zone (ITZ). This is the zone of bonding between the aggregate and the cementitious matrix. Greater adherence between these two components will imply less slippage in these zones and, therefore, greater stiffness when loads are applied [14]. Adherence depends on the surface properties of the aggregate and the nature of the cementitious matrix [15].

The variability of the modulus of elasticity is already noticeable in concrete made with conventional materials [16], i.e., natural aggregate and standardized cement (EN 197-1 [17]). The different properties of a cementitious matrix, such as binder type, porosity, admixtures, and ultrafine aggregate fractions, as well as the different characteristics of each aggregate, which vary from one geographical location to another, cause notable variations in the modulus of elasticity [18]. In addition, the different compositions of each type of concrete (self-compacting concrete, high-performance concrete, vibrated concrete...) [19] condition both the volume of aggregate added to a concrete mix and the properties and microstructure of the resulting cementitious matrix [20]; aspects that also affect the value of the global elasticity modulus of the concrete [1]. Due to the large number of factors that might affect the elasticity modulus of concrete [21], structural design standards include statistical formulas for its estimation, generally in relation to the compressive strength of the material [16,
22]. These expressions are based on the statistical fitting of large volumes of experimental data.

The pursuit of greater sustainability in the construction sector has led to the widespread use of wastes and industrial by-products as substitutes for natural aggregates in concrete [23]. The alternative aggregates that can be used are very varied, though the most common are electric arc furnace slag (EAFS) [24], recycled concrete aggregate [20], glass [25], and rubber [26]. This practice has reduced the volume of aggregate extraction from quarries and gravel pits and as a result has lessened the environmental impact of extractive industries [27]. However, it has significantly hindered the prediction of the modulus of elasticity of concrete for two reasons. On the one hand, alternative aggregates cover a much wider range of stiffness values [1]. Moreover, the adherence of the above-mentioned alternative aggregates within cementitious matrices differs with respect to the adherence of the natural aggregates [28]. The use of alternative aggregates in all types of concrete has therefore meant that highly variable moduli of elasticity have been reported in the literature. Furthermore, the statistical formulae cited in international standards $[16,22]$ for the estimation of the modulus of elasticity of concrete are no longer valid [29] when these alternative aggregates are used.

The problem of variations in the modulus of elasticity of concrete has been addressed in various studies that have sought to estimate this mechanical property when a certain alternative aggregate is used [30]. The efforts of researchers have to date been limited to statistical studies in which patterns have been observed of the effect of each type of alternative aggregate on the modulus of elasticity [31]. Again, this procedure relies on fitting a large amount of experimental data to theoretical predictions [1]. However, no procedure has been reported in the literature for estimating the elastic stiffness of the aggregate-ITZ system. The elasticity of the aggregate-ITZ system can be defined as the modulus of elasticity of the aggregate suitably corrected by the slippage between the aggregate and the surrounding cementitious matrix when loading is applied [14]. The elastic stiffness of the aggregate-ITZ system therefore depends both on the type of aggregate and on its interaction with the surrounding cementitious matrix; adherence will not only differ when changing the aggregate type, but it will also differ when modifying the composition of the cementitious matrix [15].

Determining the elastic stiffness of the aggregate-ITZ system will provide greater insight into the effect of using a particular type of aggregate on the modulus of elasticity of the resulting concrete. In addition, if the elastic stiffness of the aggregate-ITZ system is measured, then the elastic modulus of concretes with different proportions of aggregate and cementitious matrix may theoretically be estimated. Furthermore, since the use of any type of alternative aggregate modifies the elastic stiffness of the aggregate-ITZ system, its use alters the 
reaction of the aggregate to the volumetric contraction/dilatation of the cementitious matrix [32]. Changes in the specific global volume variation of concrete (due to drying shrinkage, differential thermic dilatation, aggregate swelling...) when a type of alternative aggregate is added can be explained by the elastic stiffness of the aggregate-ITZ system [33].

In this paper, the intention is to propose a simple procedure for estimating the elastic stiffness of the aggregate-ITZ system in a concrete mix, based on the dependence of the elastic stiffness of the cementitious matrix upon its porosity, and the relative volumes of aggregate and cementitious matrix that compose the concrete. In addition, it is shown how this method can be used to estimate the modulus of elasticity of concrete mixtures containing the same aggregates and cementitious matrices with the same composition. The study is complemented with the estimation of the elastic stiffness of limestone-ITZ and EAFS-ITZ systems in a slag-based cementitious matrix, examples which serve as a validation of the method for estimating the elastic moduli of different types of concrete.

\section{Procedure for the determination of the elastic stiffness of an aggregate-ITZ system}

\subsection{Estimation of the elastic stiffness of an aggregate-ITZ system}

In principle, the cementitious matrix and the aggregate are randomly distributed within concrete (first hypothesis), as illustrated in Fig. 1a. Therefore, since each cross-section in the direction of load application will contain different percentages of aggregate and cementitious matrix (Fig. 1b), both materials may be subjected to different stresses when a load is applied (Fig. 1c). The applied load will, therefore, be distributed between both components in proportion to its area. Therefore, Eq. 1 is satisfied $\left(L_{c}\right.$, load supported by the concrete; $L_{c m}$, load supported by the cementitious matrix; $L_{a-I T Z}$, load supported by the aggregate).

$L_{c}=L_{c m}+L_{a-I T Z}$

Transforming Eq. 1 in terms of stress yields Eq. 2 $\left(\sigma_{c}\right.$, stress within concrete; $A_{c}$, area of concrete; $\sigma_{c m}$, stress within cementitious matrix; $A_{c m}$, area of cementitious matrix; $\sigma_{a-I T Z}$, stress within aggregate; $A_{a-I T Z}$, area of aggregate).

$\sigma_{c} \times A_{c}=\sigma_{c m} \times A_{c m}+\sigma_{a-I T Z} \times A_{a-I T Z}$

Dividing Eq. 2 by the concrete area $\left(A_{c}\right)$ yields Eq. 3 .

$\sigma_{c}=\sigma_{c m} \times \frac{A_{c m}}{A_{c}}+\sigma_{a-I T Z} \times \frac{A_{a-I T Z}}{A_{c}}$.

The ratios of the area of cementitious matrix or aggregate to the area of concrete correspond to the volumetric fraction or relative volume of each component in the concrete. In this statement, it is considered that the cross-sections with a larger aggregate area are compensated by those with a smaller aggregate area. Therefore, Eq. 3 can be expressed as Eq. 4 ( $V_{c m}$, relative volume of cementitious matrix in concrete; $V_{a-I T Z}$, relative volume of aggregate in concrete).
Fig. 1 First hypothesis: a random distribution of aggregate; $\mathbf{b}$ sections with varying proportions of aggregate and cementitious matrix; c stress distribution between aggregate and cementitious matrix in a representative section (a)

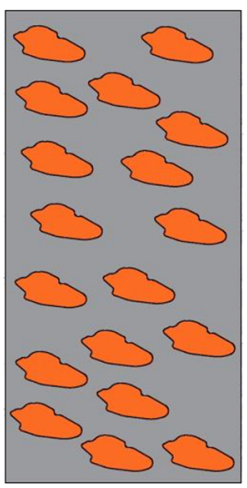

(b)

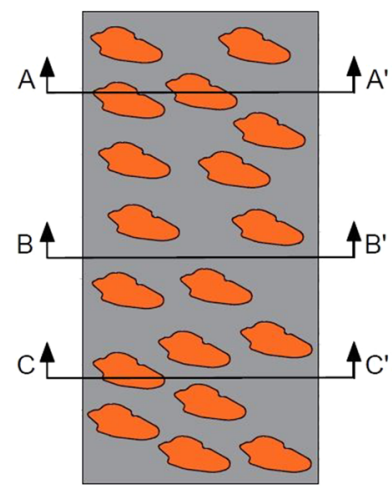

Aggregate

Cementitious matrix
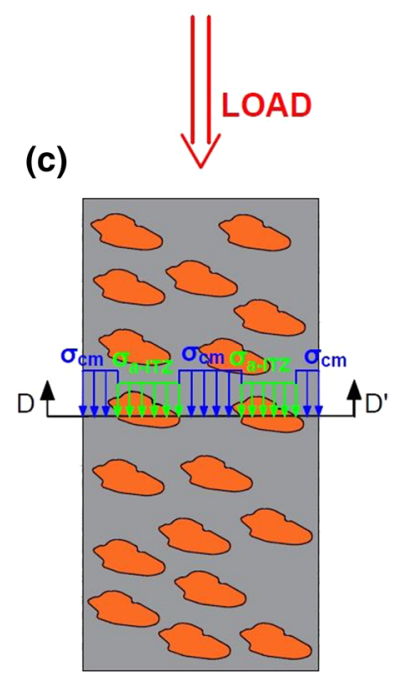

LOAD 
$\sigma_{c}=\sigma_{c m} \times V_{c m}+\sigma_{a-I T Z} \times V_{a-I T Z}$

If Eq. 4 is divided by the concrete strain, Eq. 5 is obtained $\left(\varepsilon_{c}\right.$ strain of concrete).

$\frac{\sigma_{c}}{\varepsilon_{c}}=\frac{\sigma_{c m}}{\varepsilon_{c}} \times V_{c m}+\frac{\sigma_{a-I T Z}}{\varepsilon_{c}} \times V_{a-I T Z}$.

On a large scale, concrete can be considered as a homogeneous material, i.e., if the concrete element is large enough, then even if it is composed of aggregate and cementitious matrix, the heterogeneity of its composition can be overlooked (second hypothesis); a hypothesis that is illustrated in Fig. 2. It may, therefore, be proposed that both the aggregate and the cementitious matrix will experience the same strain. Equation 5 is thereby transformed into Eq. $6\left(\varepsilon_{c m}\right.$, strain of the cementitious matrix; $\varepsilon_{a-I T Z}$, strain of the aggregate together with the slippage effect within the ITZ). It makes no sense to introduce the influence of the ITZ in terms of stress, but it does make sense in terms of strain when considering slippage between the aggregate and the cementitious matrix [14].

$\frac{\sigma_{c}}{\varepsilon_{c}}=\frac{\sigma_{c m}}{\varepsilon_{c m}} \times V_{c m}+\frac{\sigma_{a-I T Z}}{\varepsilon_{a-I T Z}} \times V_{a-I T Z}$.

Considering the quotient between the stress that is applied and the induced a level of strain within any material in the elastic field yields the modulus of elasticity of that material, Eq. 7 is obtained $\left(E_{C}\right.$, modulus of elasticity of concrete; $E_{c m}$, modulus of elasticity of the cementitious matrix; $E_{a-I T Z}$, modulus of elasticity of the aggregate-ITZ system).
$E_{c}=E_{c m} \times V_{c m}+E_{a-I T Z} \times V_{a-I T Z}$.

Considering Eq. 7, it is possible to obtain the modulus of elasticity (elastic stiffness) of the aggregate-ITZ system by deduction, through Eq. 8:

$E_{a-I T Z}=\frac{E_{c}-E_{c m} \times V_{c m}}{V_{a-I T Z}}$.

This formulation is similar to one in the literature for the estimation of the modulus of elasticity of a material composed of a matrix and fibers when a load is applied in the direction of the fibers [34]. In principle, concrete is far from being a material with such characteristics, although the experimental results in Sect. 3 will show that this approximation is valid and acceptably accurate. A formulation similar to that described, obtained by applying the principle of equivalent strains, could have been obtained by applying the principle of energy equivalence.

\subsection{Estimation of the modulus of elasticity of the cementitious matrix}

According to the previous section, the modulus of elasticity of concrete, the relative volumes of aggregate plus ITZ and cementitious matrix within a concrete, and the modulus of elasticity of the cementitious matrix, must all be known, to estimate the elastic stiffness of the aggregate-ITZ system. The modulus of elasticity of concrete can be experimentally measured, for which purpose specific procedure may be found in the relevant standard (EN 12390-13 [17]). Alternatively, the relative volume of the aggregate-ITZ system can be approximated using the volume of aggregates,
Fig. 2 Second hypothesis: comparison of small-scale heterogeneity with large-scale homogeneity

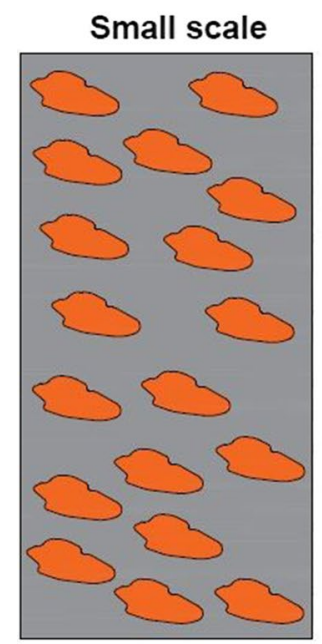

Aggregate

Cementitious matrix 
considering the small size (thickness) of the ITZ. Hence, the relative volumes of both the cementitious matrix and the aggregate can be easily determined from the composition of the concrete and the density of its components. The modulus of elasticity of the cementitious matrix is, therefore, all that remains to be determined.

It has been accepted since the mid-twentieth century that the compressive strength of a ceramic material containing small-sized pores of variable morphology, such as the cementitious matrix of concrete, can be estimated by Eq. 9 [35]. In this equation, $\sigma$, is the compressive strength of the porous ceramic material; $\sigma_{0}$, the strength of the ceramic material with null porosity; $k$, an exponential fit constant; $P$, the porosity of the ceramic material in volumetric unitary fraction.

$\sigma=\sigma_{0} \times e^{-k \times P}$.

This formulation is extended for estimating the modulus of elasticity of a porous ceramic material, as shown in Eqs. 10 and 11. In this expression, $E$ is the modulus of elasticity of the porous ceramic material, and $E_{0}$ is the modulus of elasticity of the ceramic material if of zero porosity.

$E=E_{0} \times e^{-k \times P}$.

$\ln \left(E_{c m}\right)=\ln \left(E_{0}\right)-k \times P$.

Therefore, if the porosity of the cementitious matrix composing concrete is measured, for example, by mercury intrusion porosimetry (MIP) or water-absorption tests, at a constant vacuolar porosity (air content), and if the model of Eq. 10 is available (i.e., coefficients $E_{0}$ and $k$ are both known), it is possible to determine the modulus of elasticity of the cementitious matrix.

Two mortar mixtures of identical composition (and vacuolar porosity) to the cementitious matrix have to be designed. Subsequently, suitable specimens must be manufactured, their porosity and modulus of elasticity measured, and adjustments made to the model (Eq. 10), to determine the two adjustment coefficients, $E_{0}$ and $k$. The two mortar mixtures that were designed must have a different capillary porosity for the adjustment to be possible, but they must also be of similar composition. The need to keep the composition of the cementitious matrices similar is not a matter of controlling the water content, as the literature has indicated [35] and the authors of this research work have experimentally verified. Simplifying the problem, two mixtures of similar composition and different porosities may be obtained, simply by varying the amount of water added (all other components remaining constant), which in turn leads to the alteration of the capillary porosity of the mortar mixture. In realistic terms, more than two mixtures should be manufactured, the air content should be controlled, and a statistical adjustment should be performed. In this study, the authors present both the ideas and the methods as well as the principles that will be applied to more detailed experimentation.

\subsection{Estimation of the modulus of elasticity of concrete}

Through the questions exposed in the former Sects. 2.1 and 2.2 , it is possible to determine the modulus of elasticity of the aggregate-ITZ system for a certain aggregate and a cementitious matrix of a specific composition. This value allows a precise understanding of the quality of the aggregate as a component of concrete, considering its own mineral nature and the suitability of the ITZ associated with its interaction with the cementitious matrices.

Let us suppose that in a concrete with a certain cementitious matrix and any type of aggregate, the elastic deformability of the aggregate-ITZ system has been determined. With this value, Eq. 7 may be used to calculate the modulus of elasticity of a concrete with the same composition, but with a different water content. For instance, if its workability should be modified, it would only be necessary to measure the capillary porosity of the cementitious matrix of this new concrete. A porosity level that could be used to determine the modulus of elasticity of the new cementitious matrix (Eq. 10) and, finally, the modulus of elasticity of the concrete. Equation 7 could also be used to calculate the elasticity modulus of concrete made with the same type of aggregate and a cementitious matrix of the same composition, but with differing proportions of both components $\left(V_{c m}\right.$ and $\left.V_{a-I T Z}\right)$. In this case, the elastic stiffness of the cementitious matrix should be calculated in the same way (Eq. 10).

The porosity of the cementitious matrix must be measured, to make the above-mentioned estimates. Nevertheless, it could be proposed that the porosity of a cementitious matrix is approximately equal to the volumetric fraction of the effective water (water not absorbed by the aggregate) [36]; hence, its modulus of elasticity could perhaps be directly estimated without measuring its porosity. The modulus of elasticity of a certain cementitious matrix when any water content is added could therefore be estimated by a linear interpolation on a logarithmic scale between the effective volumetric fractions of water (with respect to the volume of the cementitious matrix) and the moduli of elasticity of the mortar mixtures developed to fit the model of Eq. 10 (constants $E_{0}$ and $k$ ). Equation 12 can be used for this purpose, in which $X_{w, x}$ is the effective-water volumetric fraction of the cementitious matrix whose modulus of elasticity, $E_{c m, x}$, is to be determined. $E_{c m, l}$ and $X_{w, l}$, respectively, represent the modulus of elasticity and the effective-water volumetric fraction of the mortar mix with the lowest porosity used to adjust the model of Eq. 10. Note that the water content of 
the cementitious matrices discussed above can be changed, but the nature and the proportion of the other components must remain constant, since their modification would imply different $E_{0}$ and $k$ coefficients [35]. Additionally, note that the elastic stiffness of the aggregate-ITZ system, measured by $E_{a-I T Z}$, will be considered regardless of the water content of the concrete mixture and any eventual change in ITZ bonding behavior due to that variable [15]. This statement is not all together evident and will be further discussed in the following sections.

$E_{c m, x}=E_{c m, 1} \times \exp \left(-k \times\left(X_{w, x}-X_{w, 1}\right)\right)$.

Finally, let us assume that an alternative aggregate has been used to produce a concrete, but that it has only been used in partial replacement of the natural aggregate. A mixture that implies a concrete with two different aggregates, two different aggregate-ITZ systems, and, therefore, two different elasticities corresponding to both systems [29]. If the two hypotheses for obtaining Eq. 8 are considered valid, the modulus of elasticity of a concrete with two different aggregates may be calculated using Eq. 13; this expression can be extended to a number $n$ of different aggregates (Eq. 14). The determination of the modulus of elasticity of the cementitious matrix could be estimated in accordance with the points indicated in the previous paragraph, although the calibration of the model to determine the elastic stiffness of the cementitious matrix (Eq. 10) and the elasticities of the aggregate-ITZ systems must have been performed on mixtures with a cementitious matrix of exactly the same composition, except for the water content.

$$
\begin{aligned}
E_{c}= & E_{c m} \times V_{c m}+E_{a-I T Z 1} \times V_{a-I T Z 1}+E_{a-I T Z 2} \times V_{a-I T Z 2} . \\
E_{c}= & E_{c m} \times V_{c m}+E_{a-I T Z 1} \times V_{a-I T Z 1} \\
& +E_{a-I T Z 2} \times V_{a-I T Z 2}+\cdots+E_{a-I T Z n} \times V_{a-I T Z n} .
\end{aligned}
$$

\subsection{Overview}

Figure 3 summarizes all the aspects addressed regarding the proposed procedure: calibration of the $E_{0}$ and $k$ coefficients, determination of the modulus of elasticity of the cementitious matrix, calculation of the elastic stiffness of the aggregate-ITZ system, and the utility of this method for estimating the elastic modulus of concrete samples.

\section{Procedural application}

The aim in this section is to show the usefulness of the procedure explained in the previous section. For this purpose, first of all, the elastic stiffnesses of limestone-ITZ and EAFS-ITZ systems in a slag-based cementitious matrix were determined. Subsequently, the moduli of elasticity of two concrete mixtures were calculated on the basis of the elastic stiffnesses of the aggregate-ITZ systems that were obtained.

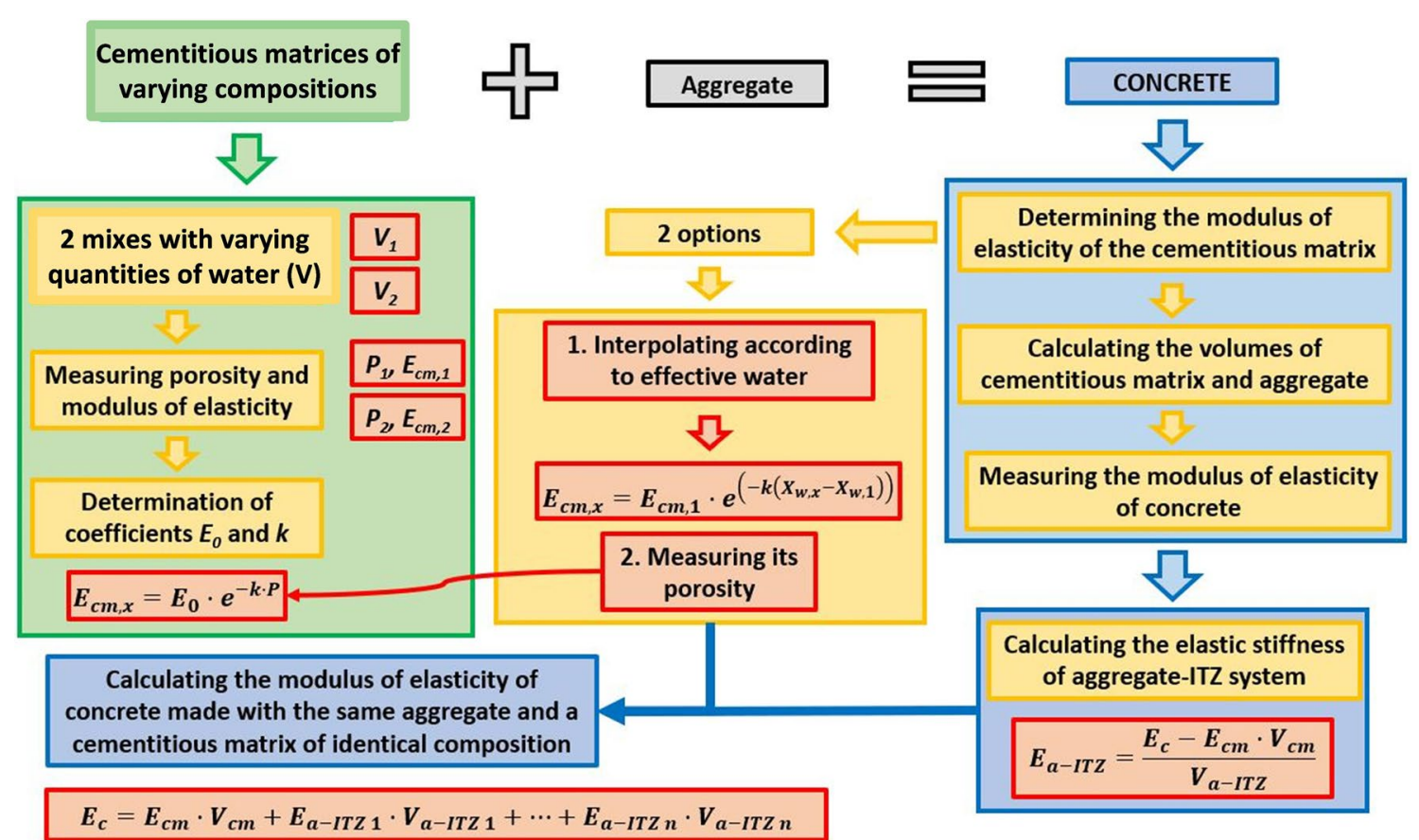

Fig. 3 Overview 


\subsection{Materials}

The cementitious matrix of the cement-based mixes developed to analyze the validity of this procedure consisted of the following components:

- CEM III/B $32.5 \mathrm{~N}$ as per EN 197-1 [17]. This cement was characterized by a content of ground granulated blast furnace slag and Portland clinker in proportions of approximately $75 \%$ and $25 \%$, respectively; its density was $2.97 \mathrm{Mg} / \mathrm{m}^{3}$. Although the validation of the proposed procedure could have been performed with any type of cement, a slag-based cement was initially chosen because it allowed the formation of a weaker cementitious matrix than ordinary Portland cement [37]. The effect of the substitution of limestone aggregate with EAFS on the elastic stiffness of the aggregate-ITZ system was determined more clearly with a low-strength cementitious matrix that showed the relevance of this value.

- Commercial limestone fines $0 / 1.18 \mathrm{~mm}$, with a fineness modulus of 1.5 units, a density of $2.65 \mathrm{Mg} / \mathrm{m}^{3}$, a $24-\mathrm{h}$ water absorption of $0.53 \%$, and a calcite content higher than $95 \%$. The use of this ultrafine fraction of aggregate was due to the scarcity of fines of EAFS, which will reduce concrete workability [24].

- Water was supplied from the mains supply network of Burgos, a city located in northern Spain, where the research took place.

The concrete was manufactured with fine gravel $(1.18 / 4 \mathrm{~mm})$ and ordinary gravel $(4 / 12 \mathrm{~mm})$. Two different aggregate types were used:

- A commercial limestone aggregate with very similar physical properties to those of limestone fines $0 / 1.18 \mathrm{~mm}$, as its density and 24-h water absorption were $2.67 \mathrm{Mg} /$ $\mathrm{m}^{3}$ and $0.46 \%$, respectively. The coarse fraction showed a fineness modulus of 5.9 units, while the fineness modulus of the medium fraction was 4.0 units.

- EAFS, which had been exposed to the environment outside the laboratory for three months for adequate aging, thus improving the in-fresh behavior of concrete [37]. This aggregate had a density of $3.42 \mathrm{Mg} / \mathrm{m}^{3}$ and a 24-h water absorption of $0.62 \%$. The fineness moduli of the coarse and the medium fractions were 5.7 and 3.9 units, respectively.

The particle sizes of all the aggregates are shown in Fig. 4. It can be seen that both limestone aggregate and EAFS had a similar gradation in both fractions $(1.18 / 4 \mathrm{~mm}$ and $4 / 12 \mathrm{~mm}$ ), so that the results obtained were widely comparable [38].

\subsection{Mix design and experimental tests}

In all, 8 mixtures were designed to validate the proposed procedure:

- 2 mortar mixes composed only of cementitious matrices (CEM III/B and limestone fines 0/1.18 mm) labelled MM1 and MM2 (mortar mixes 1 and 2). The only difference between them was the water content (water-tocement ratios of 0.32 and 0.37 , respectively), modified to obtain a different porosity [35]. These two mixes were used to calibrate the model that provided the modulus of elasticity of the cementitious matrix (Eq. 10), thus determining coefficients $E_{0}$ and $k$.

- 2 concrete mixes with limestone aggregate, labelled LCM1 and LCM2 (limestone concrete mixes 1 and 2). Both had the same composition, except for the water con-
Fig. 4 Gradation of the aggregates

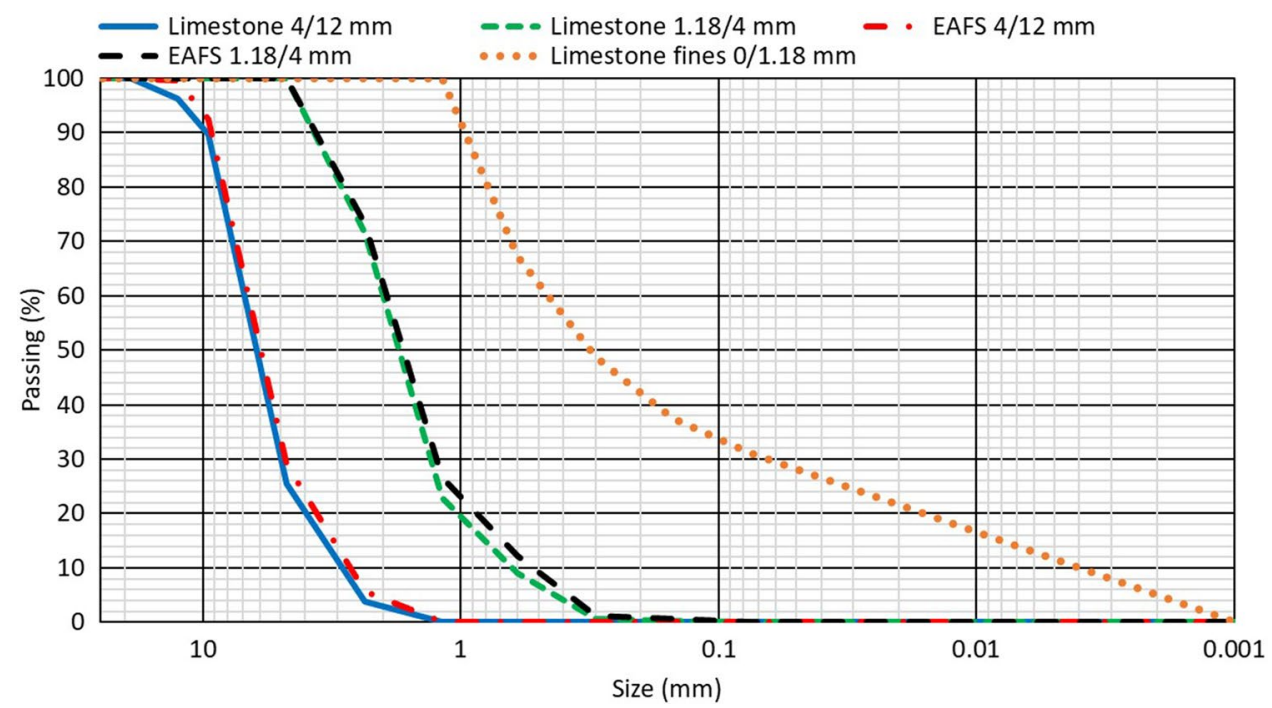


tent, which was modified to verify that the porosity of the cementitious matrix had no effect on the elastic stiffness of the limestone-ITZ system. The composition of the cementitious matrix was the same as for mortar mixes MM1 and MM2.

- 2 concrete mixes with EAFS, labelled SCM1 and SCM2 (slag concrete mixes 1 and 2). Both were designed with the same composition as the limestone concrete mixes (same water content), substituting one aggregate for another by volume correction. The objective was to obtain a value of the modulus of elasticity of the EAFSITZ system fully comparable with that of the limestoneITZ system in two mixes of different porosity.

- Finally, 2 concrete mixes with different proportions of aggregate (limestone and EAFS) and cementitious matrix were used to calculate their modulus of elasticity through the procedure that has been developed. These mixtures were labelled VM1 and VM2 (validation mixes 1 and 2). Mix VM1 was made with 50\% limestone aggregate and $50 \%$ EAFS and had a different proportion of cementitious matrix and aggregate than mixes LCM1, LCM2, SCM1, and SCM2. Mix VM2 was identical to mix VM1, except that it had $100 \%$ EAFS and no limestone aggregate.

In all the mixes, the ratio between the amounts of limestone fines $0 / 1.18 \mathrm{~mm}$ and cement was equal to 2 , so that the composition of the cementitious matrix was the same in all of them. The proportion of each component was defined according to the specifications of Eurocode 2 [16] to obtain a concrete consistency of class S3 (EN 206 [17]), seeking likewise a closer fit with the Fuller curve. Consistency class S3 was chosen because it is very common in commercial concrete production [39], although the value was irrelevant in this study. In fact, workability was not accurately measured in the mixes. Table 1 shows the composition of all these mixes, while Fig. 5 shows the overall gradation of the concrete mixes.
Regarding the mixing process, first, the aggregates were mixed for $1 \mathrm{~min}$. Subsequently, cement and water were added, and the concrete was mixed for another $2 \mathrm{~min}$. Twenty liters per mortar/concrete mix were produced. Once the mixing process had finished, six $100 \times 200-m m$ cylindrical specimens were prepared for each mixture. The specimens were stored in a humid chamber (temperature of $20 \pm 2{ }^{\circ} \mathrm{C}$ and humidity of $95 \pm 5 \%$ ) until the testing ages. The modulus of elasticity was tested (average of 4 specimens) at 7, 28, 90, and 180 days according to EN 12390-13 [17] and a 28-day compressive strength (average of 2 specimens) as per EN 12390-3 [17]. After the compressive-strength tests, concrete fragments were taken to measure porosity by mercury intrusion porosimetry (MIP) in all the mixtures, except in the validation mixtures VM1 and VM2. There was no variation in the capillary porosity of the cementitious matrix with age after 7 days [40] so a single measurement was considered valid for all ages.

\subsection{Elastic stiffness of limestone-ITZ and EAFS-ITZ systems}

\subsubsection{Coefficients $E_{0}$ and $k$}

The mechanical properties of mixes MM1 and MM2, as well as the results of the MIP tests, are shown in Table 2. Note that all experimental results may be assumed to be slightly imprecise, with their corresponding uncertainty. Figure 6 shows the log-differential intrusion and cumulative intrusion of both mixtures.

As expected, an increased content of water was accompanied, at the same time, by a decrease in the compressive strength and the modulus of elasticity at all ages. These changes are explained by the increase in porosity, reflected in the MIP results [39]. In addition, the higher water content led to a larger proportion of smaller pore sizes, so that the log-differential intrusion curve of mix MM2 had a higher slope for pore sizes between 20 and $70 \mathrm{~nm}$ than mix MM1.
Table 1 Mix composition ( $\mathrm{kg}$ per cubic meter)

\begin{tabular}{lllllllll}
\hline Component & MM1 & MM2 & LCM1 & LCM2 & SCM1 & SCM2 & VM1 & VM2 \\
\hline CEM III/B 32.5 N & 710 & 710 & 355 & 355 & 355 & 355 & 315 & 315 \\
Water & 225 & 260 & 110 & 130 & 110 & 130 & 100 & 100 \\
Limestone fines 0/1.18 mm & 1415 & 1415 & 710 & 710 & 710 & 710 & 630 & 630 \\
Limestone 1.18/4 mm & 0 & 0 & 550 & 550 & 0 & 0 & 310 & 0 \\
Limestone 4/12 mm & 0 & 0 & 760 & 760 & 0 & 0 & 425 & 0 \\
EAFS 1.18/4 mm & 0 & 0 & 0 & 0 & 710 & 710 & 400 & 800 \\
EAFS 4/12 mm & 0 & 0 & 0 & 0 & 980 & 980 & 550 & 1100 \\
Fresh volume (m ${ }^{3}$ ) & 1.00 & 1.06 & 1.00 & 1.03 & 1.00 & 1.03 & 1.00 & 1.00 \\
Effective-water volumetric fraction & 0.219 & 0.240 & 0.215 & 0.271 & 0.213 & 0.268 & 0.221 & 0.219 \\
$\quad($ as per volume of cementitious & & & & & & & & \\
$\quad$ matrix) & & & & & & & &
\end{tabular}


Fig. 5 Joint gradation of the mixes

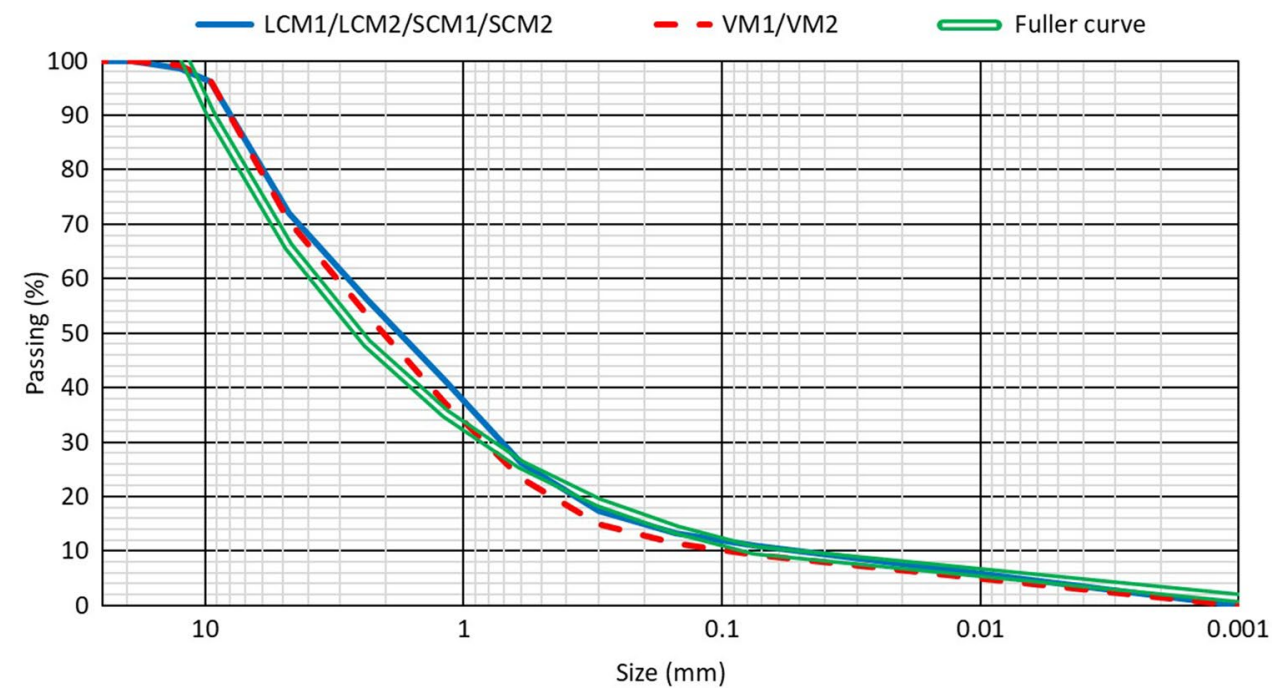

Table 2 Mechanical properties and MIP results of mixes MM1 and MM2

\begin{tabular}{lll}
\hline Property & MM1 & MM2 \\
\hline 28-Day compressive strength $(\mathrm{MPa})$ & $39.8 \pm 0.5$ & $35.5 \pm 0.6$ \\
7-Day modulus of elasticity $(\mathrm{GPa})$ & $25.1 \pm 0.2$ & $15.2 \pm 0.3$ \\
28-Day modulus of elasticity $(\mathrm{GPa})$ & $27.8 \pm 1.5$ & $16.1 \pm 0.5$ \\
90-Day modulus of elasticity $(\mathrm{GPa})$ & $29.3 \pm 1.1$ & $16.6 \pm 0.3$ \\
180-Day modulus of elasticity $(\mathrm{GPa})$ & $30.4 \pm 1.1$ & $17.2 \pm 0.2$ \\
Apparent density, MIP $\left(\mathrm{Mg} / \mathrm{m}^{3}\right)$ & 2.34 & 2.31 \\
Bulk density, MIP $\left(\mathrm{Mg} / \mathrm{m}^{3}\right)$ & 2.06 & 1.93 \\
Porosity, MIP $(\%)$ & 11.7 & 16.4 \\
\hline
\end{tabular}

From the experimental values of the modulus of elasticity at each age, Table 2, the coefficients $E_{0}$ and $k$ from Eq. 10 can be calculated at each age, as shown in Table 3. The observed variations in $E_{o}$ can be explained by the progressive appearance of hydration products and the disappearance of non-hydrated binder, in such a way that the values were coherent with the classic values of elastic moduli in ioniccovalent salts. Moreover, the more modest variations of the $k$ value were consistent with the variations in mortar porosity throughout the 7-to-180-day test period.

With these coefficients, it would be possible to calculate the modulus of elasticity of the cementitious matrix at 7 , 28,90 , and 180 days simply by measuring its porosity. For example, the 28-day modulus of elasticity $\left(E_{c m, 28}\right)$, in GPa, for any value of porosity $(P)$ could be calculated by Eq. 15 , while the modulus of elasticity at 90 days $\left(E_{c m, 90}\right)$ could be obtained through Eq. 16.

$E_{c m, 28}=108.26 \times e^{-11.62 \times P}$.
$E_{c m, 90}=120.56 \times e^{-12.09 \times P}$.

Nevertheless, Eq. 10 could be generalized by expressing the two coefficients, $E_{0}$ and $k$, as functions of concrete age $(t)$. To do so, a least-squares simple regression was performed. Figure 7 shows the most accurate simple regression models for the coefficients of these cementitious-matrix mixtures after maximizing the coefficient $R^{2}$. Thus, the modulus of elasticity of the cementitious matrix at any age $\left(E_{c m, t}\right)$ could be calculated by Eq. 17 . This formula could be expressed generically by Eq. 18, in which the coefficients $A, B, C$, and $D$ could be calculated with a multiple regression. Equation 18 may, therefore, be considered valid for all cementitious matrices, regardless of their composition, assuming that a quasi-logarithmic/reciprocal development of the elastic stiffness over time is adequate for all binder types and their combinations [41].

$E_{c m, t}=(\sqrt{2982.33+2520.45 \times \ln (t)}) \times e^{-(1 /(0.082+0.081 / t)) \times P}$.

$E_{c m, t}=(\sqrt{A+B \times \ln (t)}) \times e^{-(1 /(C+D / t)) \times P}$.

Having fitted Eq. 18 by multiple regression to the experimental data of mixtures MM1 and MM2, coefficients $A, B$, $C$, and $D$ showed values of $6888.28,1441.80,0.085$, and 0.011 . The coefficient $R^{2}$ was equal to 0.9980 . The difference between these coefficient values and those reported in Eq. 17 is justified, because multiple regression provides a better fit, by simultaneously fitting all the data. Therefore, multiple regression is always recommended in these situations. Equation 19 shows the resulting multiple regression model. 

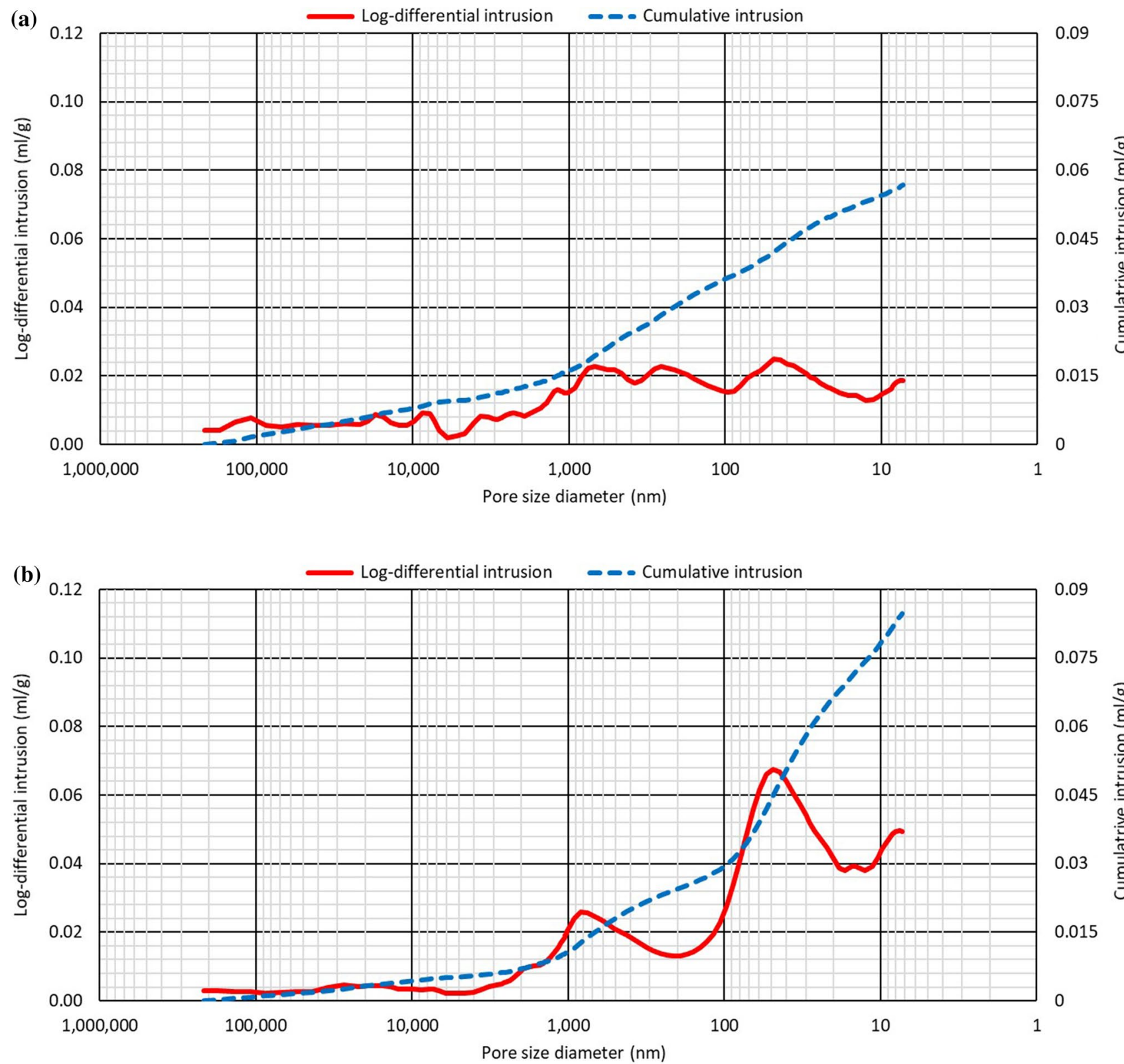

Fig. 6 Log-differential intrusion and cumulative intrusion of mixes: a MM1; b MM2

$$
E_{c m, t}=(\sqrt{6888.28+1441.80 \times \ln (t)}) \times e^{-(1 /(0.085+0.011 / t)) \times P} .
$$

Table 3 Coefficients $E_{0}$ and $k$

\begin{tabular}{lrl}
\hline Age & $E_{0}(\mathrm{GPa})$ & \multicolumn{1}{l}{$k$} \\
\hline 7 days & 87.46 & 10.67 \\
28 days & 108.26 & 11.62 \\
90 days & 120.56 & 12.09 \\
180 days & 125.54 & 12.12 \\
\hline
\end{tabular}

\subsubsection{Limestone-ITZ system}

The elastic stiffness of the limestone-ITZ system was determined using mixes LCM1 and LCM2. Each mix was prepared with a different quantity of water and had a different porosity level, to evaluate the effect of porosity on this value. The mechanical properties of both mixtures are shown in Table 4, while Fig. 8 shows the graphs corresponding to the MIP tests.

The observed behavior of these mixtures was the same as in mixes MM1 and MM2: the increase in water content and porosity worsened the mechanical behavior [36]. 


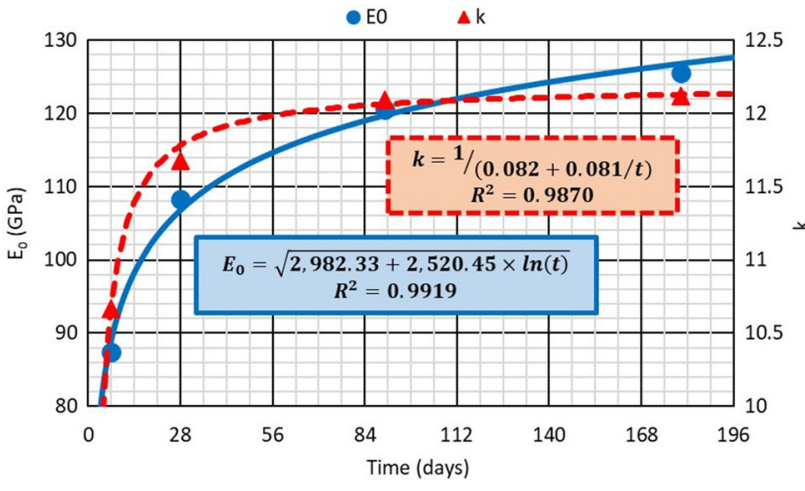

Fig. 7 Evolution of $E_{0}$ and $k$ over time

Table 4 Mechanical properties and MIP results of mixes LCM1 and LCM2

\begin{tabular}{lll}
\hline Property & LCM1 & LCM2 \\
\hline 28-Day compressive strength $(\mathrm{MPa})$ & $25.8 \pm 1.9$ & $18.1 \pm 0.7$ \\
7-Day modulus of elasticity $(\mathrm{GPa})$ & $20.8 \pm 0.4$ & $14.9 \pm 0.4$ \\
28-Day modulus of elasticity $(\mathrm{GPa})$ & $23.8 \pm 1.9$ & $16.5 \pm 0.5$ \\
90-Day modulus of elasticity $(\mathrm{GPa})$ & $25.0 \pm 1.8$ & $17.5 \pm 0.2$ \\
180-Day modulus of elasticity $(\mathrm{GPa})$ & $25.6 \pm 0.7$ & $18.1 \pm 0.3$ \\
Apparent density, MIP $\left(\mathrm{Mg} / \mathrm{m}^{3}\right)$ & 2.48 & 2.26 \\
Bulk density, MIP $\left(\mathrm{Mg} / \mathrm{m}^{3}\right)$ & 2.19 & 1.88 \\
Porosity, MIP $(\%)$ & 11.5 & 17.4 \\
\hline
\end{tabular}

Once again, higher porosity implied a higher proportion of smaller pore sizes, as shown by the log-differential intrusion in Fig. 8. In general, pore size distributions similar to those of mixes MM1 and MM2 were foreseeable and expected; in mix LCM1, a surprising abundance of around-100-nm pores was detected, although this circumstance was neglected due to its low importance.

Since the porosity of these mixtures was explicitly measured, the modulus of elasticity of the cementitious matrix could be determined using Eq. 10 and the coefficients listed in Table 3. Equation 19 could also be used, in which these coefficients are adjusted as a function of the age of the concrete. Likewise, if the porosity was unknown, Eq. 12 could also be used. Regardless of the chosen option, the value of the elastic stiffness of the limestone-ITZ system can be determined by Eq. 8. It should therefore be considered that, in mix LCM1, the cementitious matrix represented 50.7\% of the volume and the limestone aggregate, $49.3 \%$. In mix LCM2, these proportions were $51.9 \%$ and $48.1 \%$, respectively, due to the higher water content. Table 5 shows the values of the elastic stiffness of the limestone-ITZ system for the cementitious matrix that was designed, calculated according to these three hypotheses at the different testing ages.
It can be observed that in both mixtures the elastic stiffness of the limestone-ITZ system was similar at each age; so that the increase in the capillary porosity (amount of water) of the mixtures had no effect on this elastic property. The values calculated using Eq. 10 and Table 3 were the most accurate, and the estimation using Eq. 19 was reasonably precise (differences of around 0.2-0.5 GPa). The estimation using Eq. 12, in which the porosity of the mixture was not measured, underestimated this elastic stiffness by $0.5-1.5$ $\mathrm{GPa}$, even though such a value can also be considered admissible.

Considering the most accurate values (Eq. 10 and Table 3), the elastic stiffness of the limestone-ITZ system of the mixes was $16.0 \mathrm{GPa}$ at 7 days, $18.9 \mathrm{GPa}$ at 28 days, $20.2 \mathrm{GPa}$ at 90 days, and $20.6 \mathrm{GPa}$ at 180 days. As the elastic stiffness of the aggregate-ITZ system depends on the evolution of adherence between the cementitious matrix and the aggregate within the ITZ, this elastic property will increase over time. If this elastic stiffness is plotted as a function of time (age of the concrete) and a simple regression is performed by maximizing the coefficient $R^{2}$, a reciprocal fit can once again be seen (Fig. 9).

\subsubsection{EAFS-ITZ system}

Mixes SCM1 and SCM2 were used to determine the elastic stiffness of the EAFS-ITZ system. For this purpose, as with the concrete mixes containing limestone aggregate, the mechanical properties of the mixes were measured at different ages and their porosity was measured by MIP. The results are shown in Table 6 and Fig. 10. The use of EAFS instead of limestone aggregate increased both the compressive strength and the modulus of elasticity at all ages, reflecting the results collected in the bibliography [42], although it also resulted in a small increase in the porosity of the cementitious matrix, due to its poorer affinity with this aggregate, as likewise shown in the literature [43]. The effect of the increased water content was the same in the mixes made with limestone aggregate, in so far as it reduced the compressive strength and modulus of elasticity.

Table 7 shows the elastic stiffness of the EAFS-ITZ system using the three procedures for the determination of this property in the limestone-ITZ system. As the composition of the concrete mixes made with limestone and EAFS was similar, because only one aggregate was substituted for the other by volume, the relative volumes of cementitious matrix and aggregate were the same as in mixes LCM1 and LCM2. Adopting the values obtained by Eq. 10 and the coefficients in Table 3, the elastic stiffness of the EAFS-ITZ system in a slag-based cementitious matrix could be considered equal to $27.1 \mathrm{GPa}$ at 7 days, $33.0 \mathrm{GPa}$ at 28 days, $34.3 \mathrm{GPa}$ at 90 days, and $34.6 \mathrm{GPa}$ at 

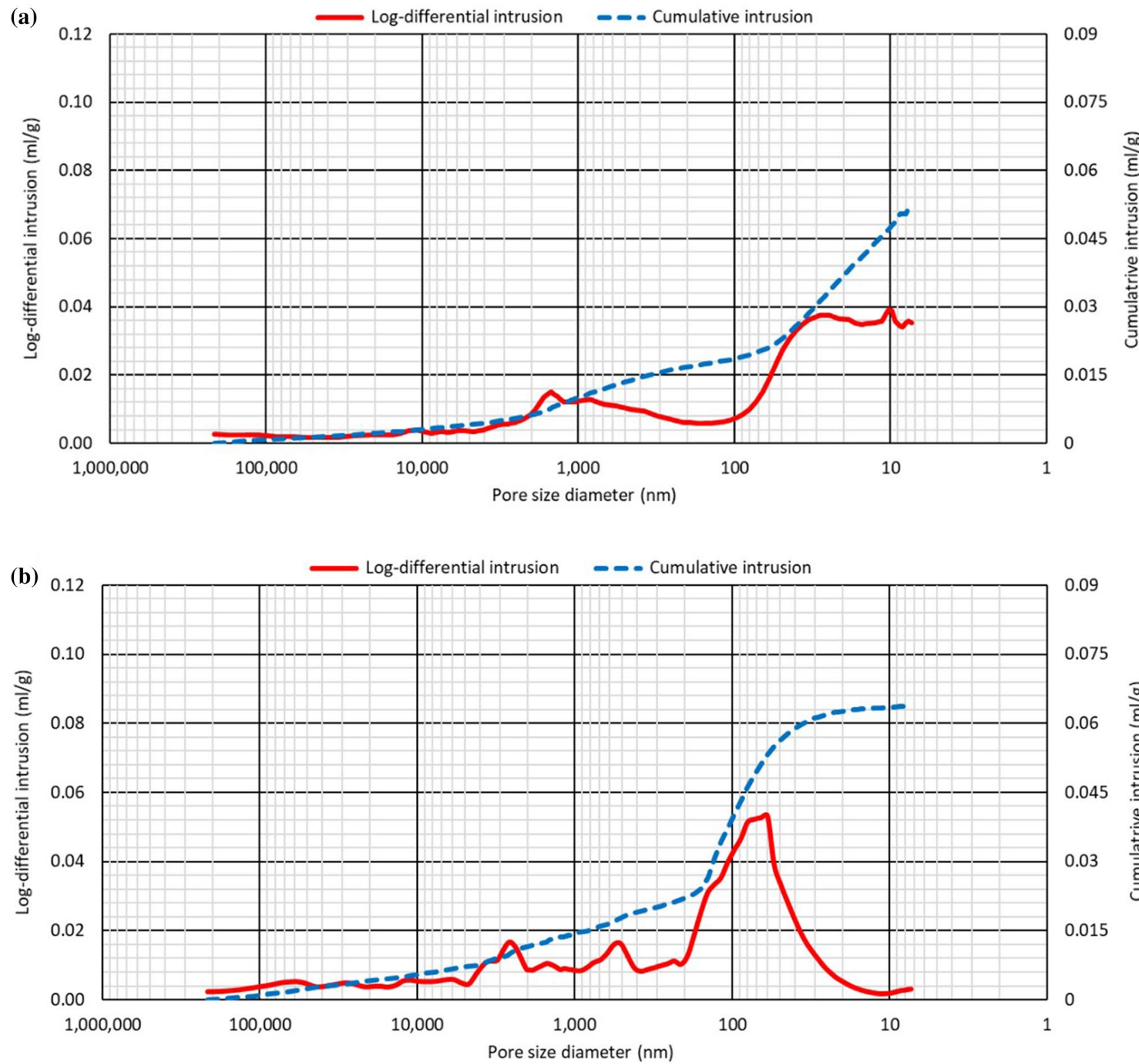

Fig. 8 Log-differential intrusion and cumulative intrusion of mixes: a LCM1; b LCM2

Table 5 Elastic stiffness of limestone-ITZ system (all values in $\mathrm{GPa}$ )

\begin{tabular}{|c|c|c|c|c|c|c|c|c|c|c|c|c|}
\hline \multirow[t]{3}{*}{ Age (days) } & \multicolumn{6}{|c|}{ LCM1 } & \multicolumn{6}{|c|}{ LCM2 } \\
\hline & \multicolumn{2}{|c|}{$\begin{array}{l}\text { Equation } 10 \\
\text { and Table } 3\end{array}$} & \multicolumn{2}{|c|}{ Equation 19} & \multicolumn{2}{|c|}{ Equation 12} & \multicolumn{2}{|c|}{$\begin{array}{l}\text { Equation } 10 \\
\text { and Table } 3\end{array}$} & \multicolumn{2}{|c|}{ Equation 19} & \multicolumn{2}{|c|}{ Equation 12} \\
\hline & $E_{c m}$ & $E_{\text {lim-ITZ }}$ & $E_{c m}$ & $E_{\text {lim-ITZ }}$ & $E_{c m}$ & $E_{\text {lim-ITZ }}$ & $E_{c m}$ & $E_{\text {lim-ITZ }}$ & $E_{c m}$ & $E_{\text {lim-ITZ }}$ & $E_{c m}$ & $E_{\text {lim-ITZ }}$ \\
\hline 7 & 25.6 & 15.8 & 26.1 & 15.4 & 26.2 & 15.3 & 13.7 & 16.2 & 13.2 & 16.7 & 14.4 & 15.4 \\
\hline 28 & 28.5 & 19.0 & 28.1 & 19.4 & 29.1 & 18.3 & 14.3 & 18.8 & 14.1 & 19.1 & 15.2 & 17.9 \\
\hline 90 & 30.0 & 19.8 & 30.0 & 19.9 & 30.8 & 19.1 & 14.7 & 20.5 & 15.0 & 20.2 & 15.6 & 19.5 \\
\hline 180 & 31.2 & 19.9 & 31.0 & 20.0 & 31.9 & 19.1 & 15.2 & 21.2 & 15.5 & 20.9 & 16.2 & 20.2 \\
\hline
\end{tabular}




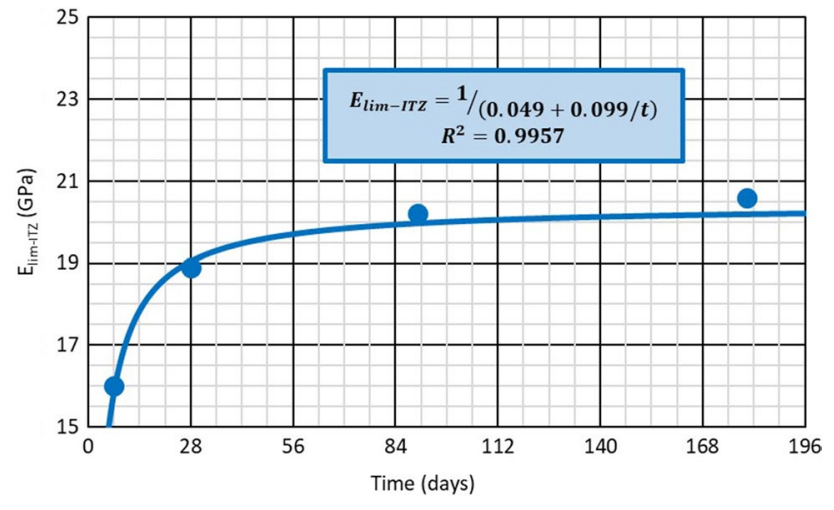

Fig. 9 Evolution of elastic stiffness limestone-ITZ system over time

Table 6 Mechanical properties and MIP results of mixes SCM1 and SCM2

\begin{tabular}{lll}
\hline Property & SCM1 & SCM2 \\
\hline 28-Day compressive strength $(\mathrm{MPa})$ & $31.3 \pm 1.7$ & $22.9 \pm 0.9$ \\
7-Day modulus of elasticity $(\mathrm{GPa})$ & $25.9 \pm 0.8$ & $18.9 \pm 0.3$ \\
28-Day modulus of elasticity $(\mathrm{GPa})$ & $29.9 \pm 1.2$ & $22.2 \pm 0.6$ \\
90-Day modulus of elasticity $(\mathrm{GPa})$ & $30.9 \pm 1.8$ & $23.2 \pm 0.2$ \\
180-Day modulus of elasticity $(\mathrm{GPa})$ & $31.5 \pm 0.5$ & $23.7 \pm 0.4$ \\
Apparent density, MIP $\left(\mathrm{Mg} / \mathrm{m}^{3}\right)$ & 3.20 & 2.95 \\
Bulk density, MIP $\left(\mathrm{Mg} / \mathrm{m}^{3}\right)$ & 2.81 & 2.45 \\
Porosity, MIP $(\%)$ & 12.4 & 18.0 \\
\hline
\end{tabular}

180 days. As for the elastic stiffness of the limestone-ITZ system, the elastic stiffness of the EAFS-ITZ system increased over time according to a reciprocal model (Fig. 11).

A comparison of the elastic stiffness of both aggregate-ITZ systems showed two relevant aspects:

- On the one hand, the elastic stiffness of the EAFSITZ system was higher than that of the limestone-ITZ system. This effect was initially due to a higher elastic stiffness of EAFS, but also to the better adherence developed between the cementitious matrix and the EAFS [37]. This higher elastic stiffness of the ITZ broadly explains the higher modulus of elasticity [42].

- The elastic stiffness of both systems increased over time, due to the strength development of the cementitious matrix, which led to increased adhesion in the ITZ [14]. However, regardless of age, the elastic stiffness of the limestone-ITZ system was equal to $60 \%$ of the elastic-stiffness of the EAFS-ITZ system. This constant ratio over time showed that ITZ quality mostly depended on the evolution of the elastic stiffness of the surrounding cementitious matrix and not on the aggregate.

\subsection{Quick estimation of the modulus of elasticity of concrete}

Two new mixes, VM1 and VM2, were prepared, to validate the procedure developed for the determination of the elastic stiffness of the aggregate-ITZ system and to show the usefulness of this value for determining the elastic modulus of a concrete. Both concrete mixes had a cementitious matrix of identical composition to the other mixes, but the proportions of matrix and aggregate were modified, and two different aggregates, limestone and EAFS, were used in VM1 (Table 1). Table 8 shows the experimentally measured moduli of elasticity of these mixtures at different ages, as well as their compressive strength. The values of these mechanical properties were in line with those of the concrete mixtures used to determine the elastic stiffness of the aggregate-ITZ systems.

Since the porosity was not measured in these concrete mixes, the modulus of elasticity of the cementitious matrix was determined on the basis of Eq. 12. The modulus of elasticity of the concrete was calculated through Eq. 14 . Table 9 shows all the values and the results of this procedure for both mixes: modulus of elasticity of the cementitious matrix $\left(E_{c m}\right)$; relative volumes of both the cementitious matrix and each aggregate $\left(V_{c m}, V_{\text {lim-ITZ }}, V_{E A F S-I T Z}\right)$; and the modulus of elasticity of the concrete $\left(E_{c}\right)$. Furthermore, the percentage deviation $(D)$ regarding the experimental value is also shown. It can be observed that the modulus of elasticity of the mixtures was overestimated at all ages, although this overestimation was only between 1 and $7 \%$, which is an acceptable value.

These results show the utility of the procedure for estimating the elastic stiffness of the aggregate-ITZ system that has been discussed in this study. Moreover, they also reflect its capability to predict the modulus of elasticity of a concrete made with a specific cementitious matrix and aggregates the stiffness of which when embedded in the cementitious matrix is known.

\subsection{Limitations of the validation}

In this section, the procedure proposed for the estimation of the elastic stiffness of the aggregate-ITZ system and, with it, of the modulus of elasticity of concrete, has been validated. The results obtained have been successful, but, nevertheless, two limitations must be considered, on which further research is needed:

- On the one hand, a traditional overall gradation of the aggregate has been considered, so that it was accurately adjusted to the Fuller curve. The modification of that gradation would imply a modification of the contact surface between the aggregate and the cementitious matrix and, 

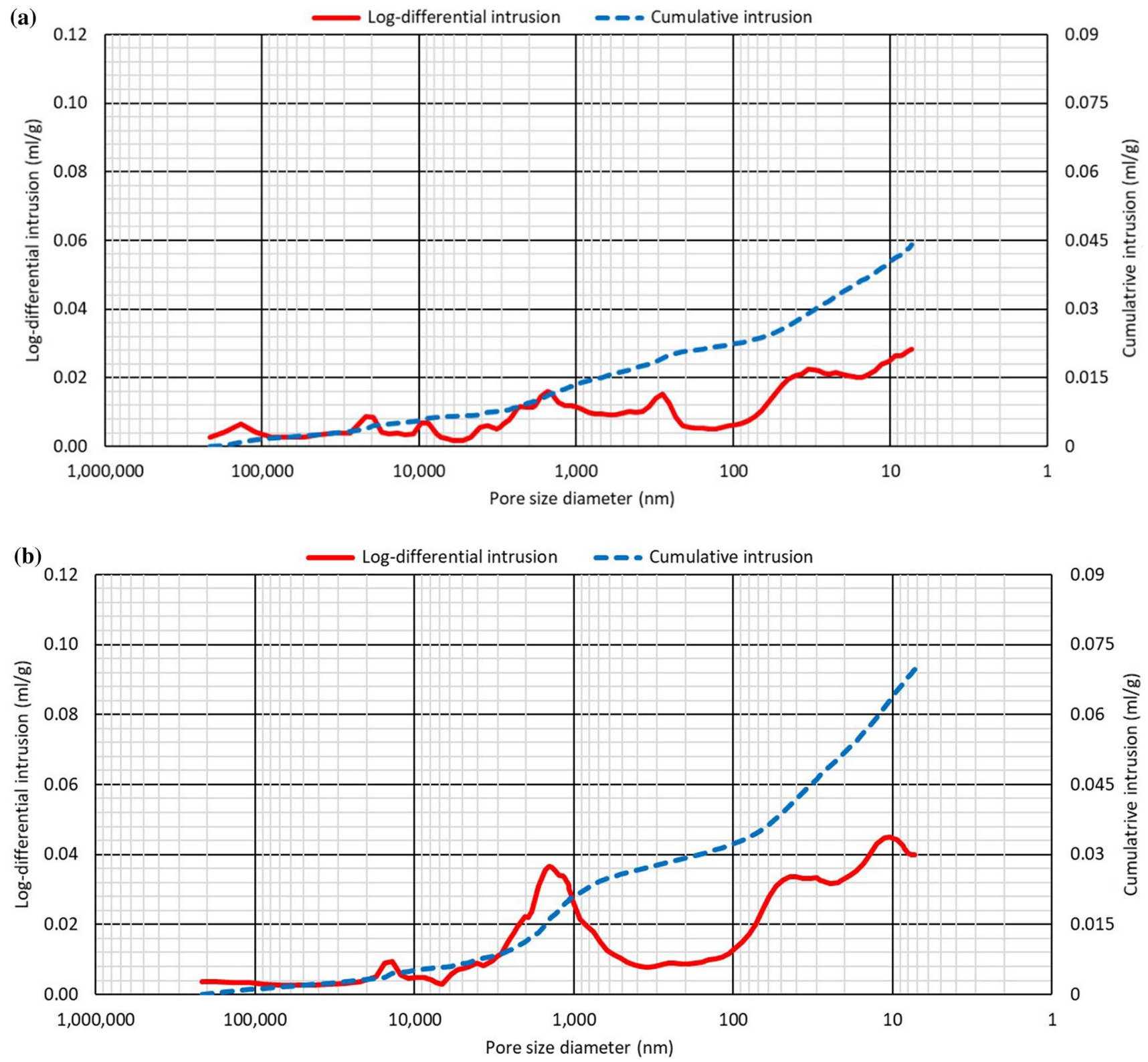

Fig. 10 Log-differential intrusion and cumulative intrusion of mixes: a SCM1; b SCM2

Table 7 Elastic stiffness of EAFS-ITZ system (all values in GPa)

\begin{tabular}{|c|c|c|c|c|c|c|c|c|c|c|c|c|}
\hline \multirow[t]{3}{*}{ Age (days) } & \multicolumn{6}{|c|}{ SCM1 } & \multicolumn{6}{|c|}{ SCM2 } \\
\hline & \multicolumn{2}{|c|}{$\begin{array}{l}\text { Equation } 10 \text { and } \\
\text { Table } 3\end{array}$} & \multicolumn{2}{|c|}{ Equation 19} & \multicolumn{2}{|c|}{ Equation 12} & \multicolumn{2}{|c|}{$\begin{array}{l}\text { Equation } 10 \text { and } \\
\text { Table } 3\end{array}$} & \multicolumn{2}{|c|}{ Equation 19} & \multicolumn{2}{|c|}{ Equation 12} \\
\hline & $E_{c m}$ & $E_{E A F S-I T Z}$ & $E_{c m}$ & $E_{E A F S-I T Z}$ & $E_{c m}$ & $E_{E A F S-I T Z}$ & $E_{c m}$ & $E_{E A F S-I T Z}$ & $E_{c m}$ & $E_{E A F S-I T Z}$ & $E_{c m}$ & $E_{E A F S-I T Z}$ \\
\hline 7 & 23.3 & 28.6 & 23.5 & 28.4 & 26.8 & 25.0 & 12.8 & 25.5 & 12.3 & 26.0 & 14.9 & 23.2 \\
\hline 28 & 25.6 & 34.3 & 25.3 & 34.6 & 29.8 & 30.0 & 13.4 & 31.7 & 13.1 & 32.0 & 15.7 & 29.2 \\
\hline 90 & 26.9 & 35.0 & 26.9 & 35.0 & 31.5 & 30.3 & 13.7 & 33.5 & 14.0 & 33.2 & 16.2 & 30.7 \\
\hline 180 & 27.9 & 35.2 & 27.9 & 35.2 & 32.7 & 30.3 & 14.2 & 34.0 & 14.4 & 33.7 & 16.8 & 31.1 \\
\hline
\end{tabular}




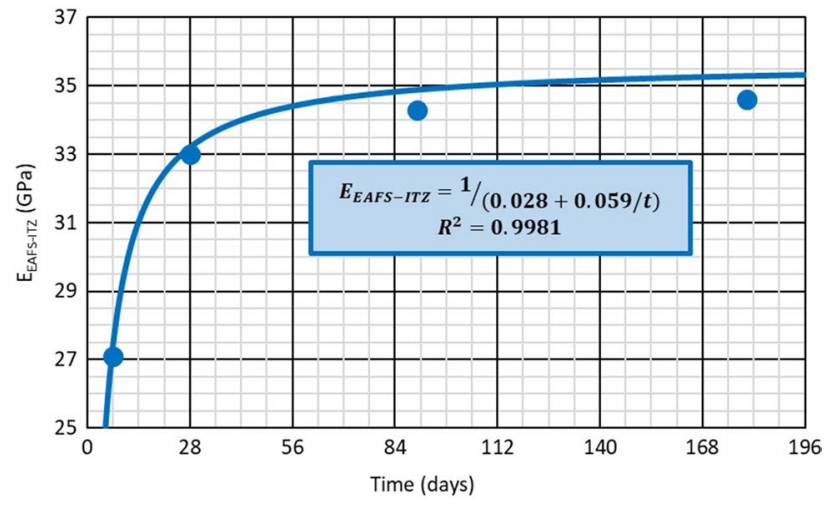

Fig. 11 Evolution of the elastic stiffness of the EAFS-ITZ system over time

Table 8 Mechanical properties and MIP results of mixes SCM1 and SCM2

\begin{tabular}{lll}
\hline Property & VM1 & VM2 \\
\hline 28-Day compressive strength (MPa) & $27.4 \pm 1.4$ & $30.5 \pm 1.1$ \\
7-Day modulus of elasticity (GPa) & $21.9 \pm 0.6$ & $24.3 \pm 0.8$ \\
28-Day modulus of elasticity (GPa) & $24.8 \pm 1.1$ & $28.8 \pm 0.7$ \\
90-Day modulus of elasticity (GPa) & $26.5 \pm 0.8$ & $30.4 \pm 0.6$ \\
180-Day modulus of elasticity (GPa) & $27.9 \pm 0.7$ & $31.8 \pm 0.7$ \\
\hline
\end{tabular}

therefore, a possible variation of the sliding level in the ITZ.

- Moreover, the validity of this procedure has been verified on $100 \times 200-m m$ cylindrical specimens by producing twenty liters of concrete per mix. The quantity of concrete produced and the size of the specimens tested may affect the second hypothesis raised during the deduction of the formulas: the homogeneous composition of concrete on a large scale. Therefore, the validity of this procedure should be tested on smaller concrete volumes and specimens, as the large-scale homogeneity hypothesis may undergo variations in those conditions.

Thus, according to the validation conducted, the procedure described above is applicable to concrete with an overall gradation of the aggregate adjusted to the Fuller curve, by preparing at least a volume of twenty liters of concrete and using $100 \times 200-\mathrm{mm}$ standardized cylindrical specimens.

\section{Conclusions}

A simple procedure to determine the elastic stiffness of aggregate-ITZ systems has been presented in this paper. It is a complex property that can be defined as the modulus of elasticity of the aggregate, suitably corrected for slippage that originates within the Interfacial Transition Zone (ITZ) between the aggregate and the cementitious matrix when loading is applied. From the application and validation of this procedure through the manufacturing of different concrete and mortar mixtures, the following conclusions can be drawn, considering that the composition of the cementitious matrix remains constant except for the water content:

- The modulus of elasticity of the cementitious matrix can be accurately estimated through the determination of its porosity (Eq. 10) using mercury intrusion porosimetry (MIP), an effective technique for porosity determination. However, if only the water content is modified, then the modulus of elasticity can also be reliably estimated by the effective-water volumetric fraction (Eq. 12).

- Knowing the modulus of elasticity of both the cementitious matrix and the concrete, the elastic stiffness of the aggregate-ITZ system can be calculated from these values and the relative volumes of aggregate and cementitious matrix (Eq. 8). To do so, it is first assumed that the load applied to concrete is distributed between the aggregate and the cementitious matrix proportionally to the area of each component. Second, concrete is considered to be a large-scale homogeneous material.

- If the modulus of elasticity of the cementitious matrix is known, as well as the elastic stiffness of all the aggregate-ITZ systems within the concrete, the modulus of elasticity of the concrete may be estimated from these values and the relative volume of each component (Eq. 14).

Table 9 Estimation of the modulus of elasticity of mixes VM1 and VM2

\begin{tabular}{|c|c|c|c|c|c|c|c|c|c|c|c|}
\hline \multirow[t]{2}{*}{ Age (days) } & \multicolumn{6}{|l|}{ VM1 } & \multicolumn{5}{|l|}{ VM2 } \\
\hline & $E_{c m}(\mathrm{GPa})$ & $V_{c m}$ & $V_{\text {lim-ITZ }}$ & $V_{E A F S-I T Z}$ & $E_{c}(\mathrm{GPa})$ & $D(\%)$ & $E_{c m}(\mathrm{GPa})$ & $V_{c m}$ & $V_{E A F S-I T Z}$ & $E_{c}(\mathrm{GPa})$ & $D(\%)$ \\
\hline 7 & 24.1 & 0.445 & 0.276 & 0.279 & 22.7 & 3.5 & 24.6 & 0.445 & 0.555 & 26.1 & 6.7 \\
\hline 28 & 26.6 & 0.445 & 0.276 & 0.279 & 26.3 & 5.6 & 27.2 & 0.445 & 0.555 & 30.5 & 5.6 \\
\hline 90 & 28.0 & 0.445 & 0.276 & 0.279 & 27.6 & 4.0 & 28.7 & 0.445 & 0.555 & 31.9 & 4.7 \\
\hline 180 & 29.1 & 0.445 & 0.276 & 0.279 & 28.3 & 1.3 & 29.8 & 0.445 & 0.555 & 32.5 & 2.3 \\
\hline
\end{tabular}


The validation of the proposed procedure was performed by determining the elastic stiffness of the limestone-ITZ and EAFS-ITZ systems. Two aspects can be highlighted from the values that were obtained:

- The elastic stiffness of the EAFS-ITZ system was the highest, which resulted in a higher strength and stiffness of the concrete mixes made with this aggregate. This value may explain a large part of the effects of replacing conventional natural aggregate with this industrial byproduct.

- The bond between the aggregate and the cementitious matrix could vary depending on the type of aggregate added, but the increase of this bond over time was less dependent of this factor. For both limestone aggregate and EAFS, the increase in the elastic stiffness of the aggregate-ITZ system over time was the same, so the increase in adherence depended on the composition of the cementitious matrix.

The procedure described in this article, as well as its validation, can be extended to a wide range of aggregates and cementitious matrices of different composition. Nevertheless, the research possibilities in this field are still very numerous. For example, the effect of admixtures on the porosity and modulus of elasticity of the cementitious matrix, or the validity of this procedure in concretes with special characteristics, such as self-compacting concrete or high-performance concrete, can be analyzed. Furthermore, the suitability of this procedure for other testing-specimen sizes or overall gradations of the aggregate could also be evaluated. Finally, the authors expect that the novel aspect of concrete addressed in this study and the procedure for its determination within such a broad range of application will be useful for studying the effects of the many alternative aggregates that are used in concrete today.

Funding Open Access funding provided thanks to the CRUE-CSIC agreement with Springer Nature. The authors wish to express their gratitude for funding this research work to the Spanish Ministry of Universities, MICINN, AEI, EU and ERDF [PID2020-113837RBI00; PID2021-124203OB-I00; RTI2018-097079-B-C31; 10.13039/501100011033; FPU17/03374]; the Junta de Castilla y León (Regional Government) and ERDF [UIC-231, BU119P17]; the Basque Regional Government through the consolidated research group SAREN [IT1619-22]; Youth Employment Initiative (JCyL) and ESF [UBU05B_1274]; and, finally, the University of Burgos [Y135.GI].

Availability of data and material All the data of this study can be provided by the authors upon request.

Code availability Not applicable.

\section{Declarations}

Conflict of interest The authors declare no conflict of interest.

Open Access This article is licensed under a Creative Commons Attribution 4.0 International License, which permits use, sharing, adaptation, distribution and reproduction in any medium or format, as long as you give appropriate credit to the original author(s) and the source, provide a link to the Creative Commons licence, and indicate if changes were made. The images or other third party material in this article are included in the article's Creative Commons licence, unless indicated otherwise in a credit line to the material. If material is not included in the article's Creative Commons licence and your intended use is not permitted by statutory regulation or exceeds the permitted use, you will need to obtain permission directly from the copyright holder. To view a copy of this licence, visit http://creativecommons.org/licenses/by/4.0/.

\section{References}

1. Silva RV, De Brito J, Dhir RK. Establishing a relationship between modulus of elasticity and compressive strength of recycled aggregate concrete. J Clean Prod. 2016;112:2171-86.

2. Revilla-Cuesta V, Skaf M, Santamaría A, Ortega-López V, Manso JM. Assessment of longitudinal and transversal plastic behavior of recycled aggregate self-compacting concrete: a two-way study. Constr Build Mater. 2021;292:123426.

3. Kazmi SMS, Munir MJ, Wu YF, Patnaikuni I, Zhou Y, Xing F. Axial stress-strain behavior of macro-synthetic fiber reinforced recycled aggregate concrete. Cem Concr Compos. 2019;97:341-56.

4. Saranya P, Nagarajan P, Shashikala AP. Performance evaluation of geopolymer concrete beams under monotonic loading. Structures. 2019;20:560-9.

5. Cao Y, Fan Q, Mahmoudi Azar S, Alyousef R, Yousif ST, Wakil $\mathrm{K}$, et al. Computational parameter identification of strongest influence on the shear resistance of reinforced concrete beams by fiber reinforcement polymer. Structures. 2020;27:118-27.

6. Al-Osta MA, Sharif AM, Ahmad S, Adekunle SK, Al-Huri M, Sharif AM. Effect of hybridization of straight and hooked steel fibers and curing methods on the key mechanical properties of UHPC. J Mater Res Technol. 2021;15:3222-39.

7. Valipour M, Khayat KH. Robustness of ultra-high-performance concrete to changes in material temperature. ACI Mater J. 2020;117(4):47-56.

8. Tenza-Abril AJ, Benavente D, Pla C, Baeza-Brotons F, ValdesAbellan J, Solak AM. Statistical and experimental study for determining the influence of the segregation phenomenon on physical and mechanical properties of lightweight concrete. Constr Build Mater. 2020;238:117642.

9. José N, Ahmed H, Miguel B, Luís E, Jorge B. Magnesia (Mgo) production and characterization, and its influence on the performance of cementitious materials: a review. Mater. 2020;13(21):4752.

10. Sousa FHF, Kazmierczak CDS, Quinino UCDM, Fernandes AJMM, Kulakowski MP. Applicability of models provided by technical standards to estimate the static modulus of elasticity of concretes produced with recycled coarse aggregates. Struct Concr. 2021;22(S1):E94-104.

11. Meng QB, Liu JF, Ren L, Pu H, Chen YL. Experimental study on rock strength and deformation characteristics under triaxial cyclic loading and unloading conditions. Rock Mech Rock Eng. 2021;54(2):777-97. 
12. Cabrera S, González A, Rotondaro R. Compressive strength in compressed earth blocks. Comparison between different test methods. Inf Constr. 2020;72(560):1-12.

13. Mohammed SI, Najim KB. Mechanical strength, flexural behavior and fracture energy of recycled concrete aggregate self-compacting concrete. Structures. 2020;23:34-43.

14. Fang G, Zhang M. The evolution of interfacial transition zone in alkali-activated fly ash-slag concrete. Cem Concr Res. 2020;129:105963.

15. Ramaniraka M, Rakotonarivo S, Payan C, Garnier V. Effect of the interfacial transition zone on ultrasonic wave attenuation and velocity in concrete. Cem Concr Res. 2019;124:105809.

16. EC-2. Eurocode 2: Design of concrete structures. Part 1-1: General rules and rules for buildings. CEN (European Committee for Standardization). 2010.

17. EN-Euronorm. Rue de stassart, 36. Belgium-1050 Brussels, European Committee for Standardization.

18. Schneider U, Schwesinger P, Debicki GS, Diederichs U, Felicetti R, Franssen JM, et al. Modulus of elasticity for service and accident conditions. Mater Struct. 2004;37(266):139-44.

19. Fuente-Alonso JA, Ortega-López V, Skaf M, Aragón Á, San-José JT. Performance of fiber-reinforced EAF slag concrete for use in pavements. Constr Build Mater. 2017;149:629-38.

20. Revilla-Cuesta V, Skaf M, Faleschini F, Manso JM, Ortega-López V. Self-compacting concrete manufactured with recycled concrete aggregate: an overview. J Clean Prod. 2020;262:121362.

21. Lanti R, Martínez M. Biaxial bending and axial load in reinforced concrete sections. Numerical approach. Inf Constr. 2020;72(558):1-9.

22. ACI-318-19. Building code requirements for structural concrete. American Concrete Institute (ACI). 2019.

23. Gupta N, Siddique R, Belarbi R. Sustainable and greener selfcompacting concrete incorporating industrial by-products: a review. J Clean Prod. 2021;284:124803.

24. Santamaría A, Orbe A, Losañez MM, Skaf M, Ortega-Lopez V, González JJ. Self-compacting concrete incorporating electric arc-furnace steelmaking slag as aggregate. Mater Des. 2017;115:179-93.

25. Adekomaya O, Majozi T. Mitigating environmental impact of waste glass materials: review of the existing reclamation options and future outlook. Environ Sci Pollut Res. 2021;28(9):10488-502.

26. Mohajerani A, Burnett L, Smith JV, Markovski S, Rodwell G, Rahman MT, et al. Recycling waste rubber tyres in construction materials and associated environmental considerations: a review. Resour Conserv Recycl. 2020;155:104679.

27. Hossain MU, Poon CS, Lo IMC, Cheng JCP. Comparative environmental evaluation of aggregate production from recycled waste materials and virgin sources by LCA. Resour Conserv Recycl. 2016;109:67-77.

28. Zhan BJ, Xuan DX, Poon CS, Scrivener KL. Characterization of interfacial transition zone in concrete prepared with carbonated modeled recycled concrete aggregates. Cem Concr Res. 2020;136:106175.
29. Revilla-Cuesta V, Ortega-López V, Skaf M, Manso JM. Effect of fine recycled concrete aggregate on the mechanical behavior of self-compacting concrete. Constr Build Mater. 2020;263:120671.

30. Han T, Siddique A, Khayat K, Huang J, Kumar A. An ensemble machine learning approach for prediction and optimization of modulus of elasticity of recycled aggregate concrete. Constr Build Mater. 2020;244:118271.

31. Bušić R, Benšić M, Miličević I, Strukar K. Prediction models for the mechanical properties of self-compacting concrete with recycled rubber and silica fume. Materials. 2020;13(8):1821.

32. Bravo M, De Brito J, Pontes J, Evangelista L. Shrinkage and creep performance of concrete with recycled aggregates from CDW plants. Mag Concr Res. 2017;69(19):974-95.

33. Gonzalez-Corominas A, Etxeberria M. Effects of using recycled concrete aggregates on the shrinkage of high performance concrete. Constr Build Mater. 2016;115:32-41.

34. Skinner HB. Composite technology for total hip arthroplasty. Clin Orthop Relat Res. 1988;235:224-36.

35. Ryshkewitch E. Compressive strength of porous sintered alumina and zirconia. J Am Ceram Soc. 1953;36(2):65-8.

36. Cantero B, Bravo M, de Brito J, Sáez-del-Bosque IF, Medina C. Water transport and shrinkage in concrete made with ground recycled concrete-additioned cement and mixed recycled aggregate. Cem Concr Compos. 2021;118:103957.

37. Ortega-López V, García-Llona A, Revilla-Cuesta V, Santamaría A, San-José JT. Fiber-reinforcement and its effects on the mechanical properties of high-workability concretes manufactured with slag as aggregate and binder. J Build Eng. 2021;43:102548.

38. Pedro D, de Brito J, Evangelista L. Mechanical characterization of high performance concrete prepared with recycled aggregates and silica fume from precast industry. J Clean Prod. 2017;164:939-49.

39. Santamaría A, Orbe A, San José JT, González JJ. A study on the durability of structural concrete incorporating electric steelmaking slags. Constr Build Mater. 2018;161:94-111.

40. Benmahiddine F, Bennai F, Cherif R, Belarbi R, Tahakourt A, Abahri K. Experimental investigation on the influence of immersion/drying cycles on the hygrothermal and mechanical properties of hemp concrete. J Build Eng. 2020;32:101758.

41. Knudsen T. The dispersion model for hydration of Portland cement I. General concepts. Cem Concr Res. 1984;14(5):622-30.

42. Amani A, Ramezanianpour AM, Palassi M. Investigation on the sustainable use of electric arc furnace slag aggregates in ecofriendly alkali-activated low fineness slag concrete as a green construction composite. J Clean Prod. 2021;307:127257.

43. Ortega-López V, Fuente-Alonso JA, Santamaría A, San-José JT, Aragón Á. Durability studies on fiber-reinforced EAF slag concrete for pavements. Constr Build Mater. 2018;163:471-81.

Publisher's Note Publisher's Note Springer Nature remains neutral with regard to jurisdictional claims in published maps and institutional affiliations. 